University of New Orleans

ScholarWorks@UNO

\title{
3-2005
}

\section{Magnetic Characterization of Nanocrystalline Nickel Ferrite Films Processed by a Spin-Spraying Method}

\author{
Gabriel Caruntu \\ University of New Orleans, gcaruntu@uno.edu \\ I Dumitru \\ Bush GG \\ Daniela Caruntu \\ University of New Orleans, dcaruntu@uno.edu \\ Charles J. O'Connor \\ University of New Orleans, coconnor@uno.edu
}

Follow this and additional works at: https://scholarworks.uno.edu/chem_facpubs

Part of the Chemistry Commons

\section{Recommended Citation}

J. Phys. D: Appl. Phys. 38 (2005) 811-815

This Article is brought to you for free and open access by the Department of Chemistry at ScholarWorks@UNO. It has been accepted for inclusion in Chemistry Faculty Publications by an authorized administrator of ScholarWorks@UNO. For more information, please contact scholarworks@uno.edu. 
Magnetic characterization of nanocrystalline nickel ferrite films processed by a spin-spraying method

This article has been downloaded from IOPscience. Please scroll down to see the full text article.

2005 J. Phys. D: Appl. Phys. 38811

(http://iopscience.iop.org/0022-3727/38/6/003)

View the table of contents for this issue, or go to the journal homepage for more

Download details:

IP Address: 137.30.164.204

The article was downloaded on 05/03/2013 at 20:26

Please note that terms and conditions apply. 


\title{
Magnetic characterization of nanocrystalline nickel ferrite films processed by a spin-spraying method
}

\author{
G Caruntu $^{1}$, I Dumitru ${ }^{1}$, G G Bush ${ }^{2}$, D Caruntu ${ }^{1}$ and \\ Charles J O'Connor ${ }^{1}$ \\ ${ }^{1}$ Advanced Materials Research Institute, Chemistry Department, University of \\ New Orleans, LA, USA \\ ${ }^{2}$ Research \& Development Division, Lockheed Missiles and Spacer Co., Palo Alto, CA, USA \\ E-mail: gcaruntu@uno.edu
}

Received 25 October 2004, in final form 19 January 2005

Published 3 March 2005

Online at stacks.iop.org/JPhysD/38/811

\begin{abstract}
Highly crystalline nickel ferrite films with different chemical compositions were processed via the spin-spraying method and their morphological, structural and magnetic properties were subsequently investigated. Regardless of the chemical composition, films with variable thicknesses are constructed by $200-400 \mathrm{~nm}$ spherical grains grown in the direction normal to the substrate surface. Magnetization measurements show that the spinel ferrite films present a hysteretic behaviour at room temperature with a randomly oriented in-plane easy axis and an anisotropy constant $K_{1} \approx-2.5 \times 10^{4} \mathrm{erg} \mathrm{cm}^{-3}$. Furthermore, the absence of an angular dependence of the coercivity for the in-plane measurement of magnetization coupled with the ' $M$ '-shaped angular dependence of the out-of-plane measurement, indicates that the anisotropy of this film is predominantly crystalline shape anisotropy.
\end{abstract}

\section{Introduction}

Recent trends in the development of microcircuitry have shed new light on transition metal ferrites as potential candidates for the next generation of electronics due to their high chemical stability and tunable magnetic properties. Magnetic semiconductors harbour promise as suitable materials for the design of a large variety of non-reciprocal devices in integrated circuits, reading-writing heads, sensors, catalysts and magnetic recording media. Soft ferrites are particularly important for the further integration of various passive circuit elements in communication devices working in the microwave range. To this end, magnetic materials should possess some key properties, such as high crystallinity, high chemical homogeneity, high magnetic permeability, induced by either a high saturation magnetization or a low uniaxial anisotropy $\left(H_{k}=10-70 \mathrm{Oe}\right)$, sufficiently low electrical conductivity and low magnetorestriction. The continuous tendency to miniaturize the electronic circuits has increased the demand for new materials with improved magnetic properties, and also having small dimensions, such as nanostructured materials or thin films. Although a large number of physical [1-4] or chemical [5-7] methods for the fabrication of magnetic thin films have been devised in the last decade, most of them are multistep synthetic approaches, which require post-synthesis heat treatment in order to ensure good crystallinity of the prepared films.

Recent efforts to obtain new, low-cost magnetic materials possessing features tailorable to various microwave applications have led to a simple, easily scalable and highly efficient one-step low-temperature method, proposed by Abe and co-workers [8]. The so-called spin-spraying method consists of the simultaneous spraying of an oxidizing solution and a treatment solution onto different kinds of substrates mounted on a rotating table. The table is maintained at a constant temperature, usually ranging from $80^{\circ} \mathrm{C}$ to $90^{\circ} \mathrm{C}$. This method is highly desirable for the deposition of transition metal ferrites on heat sensitive substrates, such as plastics or 
semiconductors. As part of an effort to expand this method to other metal ferrite films, this paper gives an account of our recent work on the synthesis and characterization of nickel ferrite films with different chemical compositions, obtained by the spin-spraying technique.

\section{Experimental details}

$\mathrm{Ni}_{x} \mathrm{Fe}_{3-x} \mathrm{O}_{4}$ films were deposited by the spin-spraying technique at $90^{\circ} \mathrm{C}$ onto glass and $\mathrm{Si}$ substrates under an inert atmosphere of nitrogen. The temperature of the substrates was maintained constant with the help of a temperature controller connected to a thermocouple encased in the rotating table. Prior to deposition, the substrates were degreased and sonicated for $15 \mathrm{~min}$, then rinsed several times and dried at room temperature. Clean substrates were mounted onto the rotating table $(200 \mathrm{rpm})$ and then exposed to two spray solutions. The oxidizing solution contained $\mathrm{NaNO}_{2}$ (3.7 $\left.\mathrm{mmol}^{-1}\right)$ and $\mathrm{CH}_{3} \mathrm{COONH}_{4}\left(48 \mathrm{mmoll}^{-1}\right)$, whereas the treatment solution contained $\mathrm{FeCl}_{2}\left(5.65 \mathrm{mmoll}^{-1}\right)$ and a suitable amount of $\mathrm{NiCl}_{2}$. Accordingly, the concentration of the nickel salt in the treatment solution was varied from 0.25 to $2 \mathrm{mmol}^{-1}$. Phase purity of the nickel ferrite films with variable thicknesses was characterized by $\mathrm{x}$-ray diffraction with a Philips X'Pert System equipped with a curved graphite single-crystal monochromator $\left(\mathrm{Cu} \mathrm{K} \mathrm{K}_{\alpha}\right.$ radiation). Patterns were recorded in a step scanning mode in the $20-95^{\circ} 2 \theta$ range with a step of $0.02^{\circ}$ and a counting time of $10 \mathrm{~s}$. The film composition was determined by both inductive plasma spectroscopy (ICP) and the film morphology was studied with both scanning electron microscopy (SEM) (JEOL 1046) and atomic force microscopy (AFM). Magnetic measurements of the films were performed at room temperature by a vibrating sample magnetometer (VSM, Lakeshore 7300) with a magnetic field up to $1 \mathrm{~T}$. Additionally, $\mathrm{x}$-band ferromagnetic resonance (FMR) experiments were performed with a $9.8 \mathrm{GHz}$ ferromagnetic resonance spectrometer (Bruker EMX 10/12). AFM experiments were carried out in contact mode with a scanning probe microscope (Digital Instruments) equipped with a $\mathrm{Si}_{3} \mathrm{~N}_{4}$ cantilever, with force constant $0.05 \mathrm{~N} \mathrm{~m}^{-1}$.

\section{Results and discussion}

Deposition of the nickel ferrite thin films on glass and silicon substrates was achieved via a three-step mechanism, which implies adsorption of transition metal ions to the substrate and partial oxidation of $\mathrm{Fe}^{2+}$ ions followed by crystallization of the ferrite film [9]. The oxidizing solution was buffered to a $\mathrm{pH}=8.5$ by adding a diluted solution of $\mathrm{NH}_{4} \mathrm{OH}$. The $\mathrm{x}$-ray diffraction patterns of the films (not shown) demonstrate that they are single phase with peaks similar to those reported for the spinel-type ferrites. Correspondingly, the x-ray peaks can be indexed into a cubic lattice. In addition, no preferred orientation was detected from the intensity of the x-ray reflections. The thickness of the films was determined by profilometry and found to range between 180 and $480 \mathrm{~nm}$, depending on the deposition time. Figure 1 illustrates the variation of the $\mathrm{Ni} / \mathrm{Fe}$ ratio as a function of the same ratio in the treatment solution. As seen in the figure, the increase of the $\mathrm{Ni}$ content in the reaction solution is accompanied by

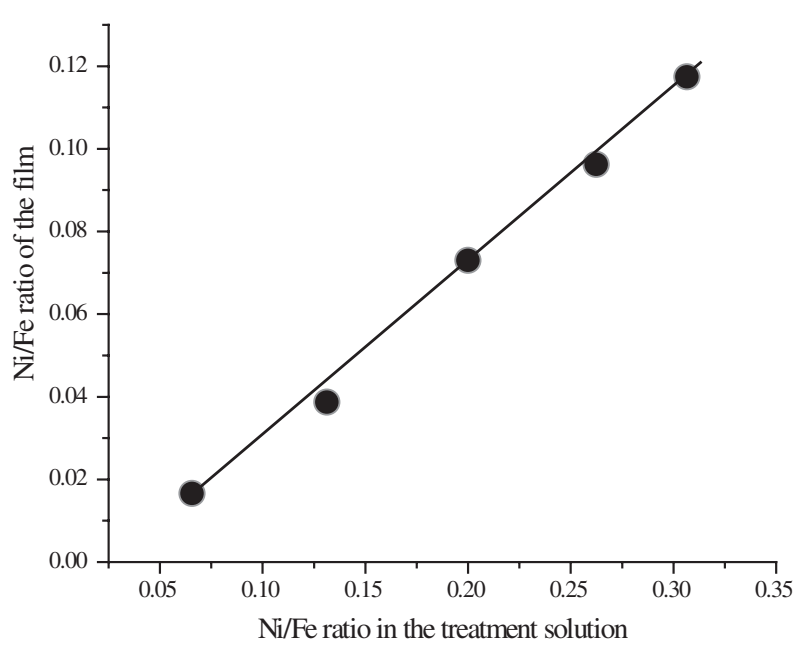

Figure 1. Variation of the $\mathrm{Ni} / \mathrm{Fe}$ ratio of the films with the $\mathrm{Ni}$ content of the treatment solution.

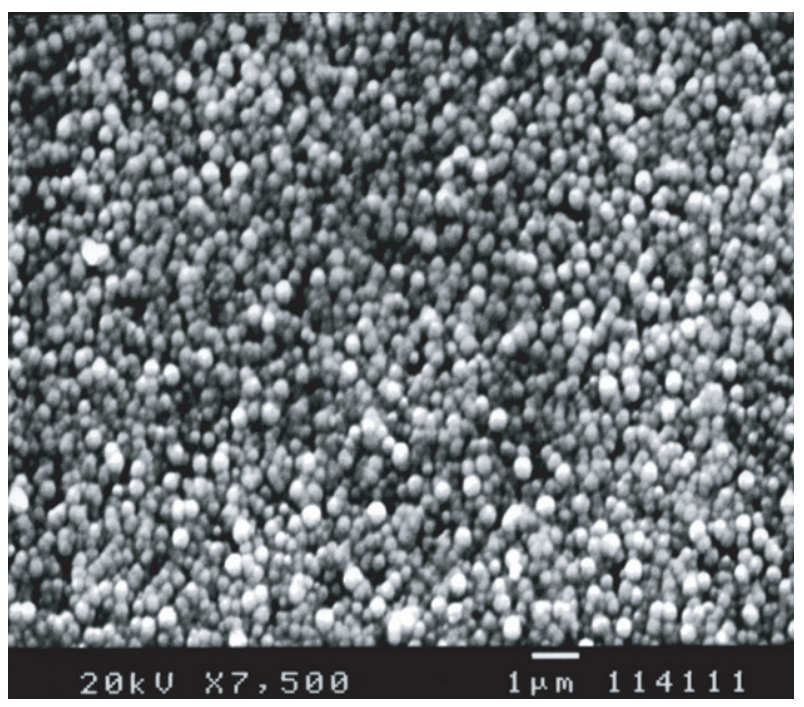

Figure 2. Top view $\mathrm{SEM}$ micrograph of the $\mathrm{Ni}_{0.32} \mathrm{Fe}_{2.68} \mathrm{O}_{4}$ film.

a roughly linear increase of the $\mathrm{Ni} / \mathrm{Fe}$ ratio in the deposited films. However, the Ni incorporation in the films is much lower than that of $\mathrm{Fe}^{2+} / \mathrm{Fe}^{3+}$, which is due to the much higher concentration of $\mathrm{Fe}^{2+}$ than $\mathrm{Ni}^{2+}$ in the treatment solution. The nickel content of the corresponding films, assuming that the $\mathrm{Fe}$ and $\mathrm{O}$ compositions are stoichiometric, was found to range between 0.13 and 0.51 . The results show that the metal content of the films can be easily controlled through the variation of the transition metal salts in the treatment solution.

Figure 2 shows a representative SEM micrograph of the $\mathrm{Ni}_{0.32} \mathrm{Fe}_{2.68} \mathrm{O}_{4}$ film with a thickness of $400 \mathrm{~nm}$. The experimental data show that regardless of the nickel content, nickel ferrite films are constructed by large arrays of uniform, welldefined spherical grains $200-400 \mathrm{~nm}$ in diameter. Thus, our films are much more morphologically homogeneous than ferrite films obtained by the same method [10]. Additionally, the nickel ferrite films presumably possess a columnar morphology [11], undetectable by top view observation during the SEM experiments. 
(a)

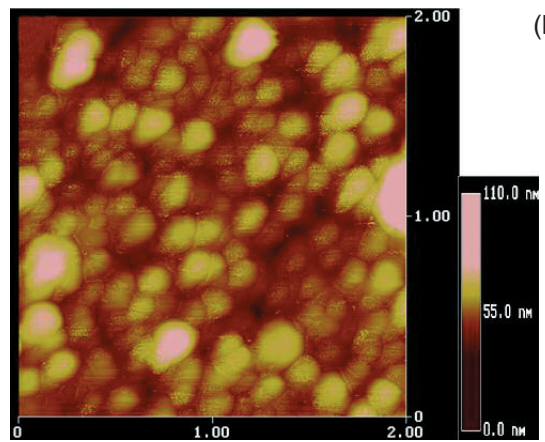

(b)

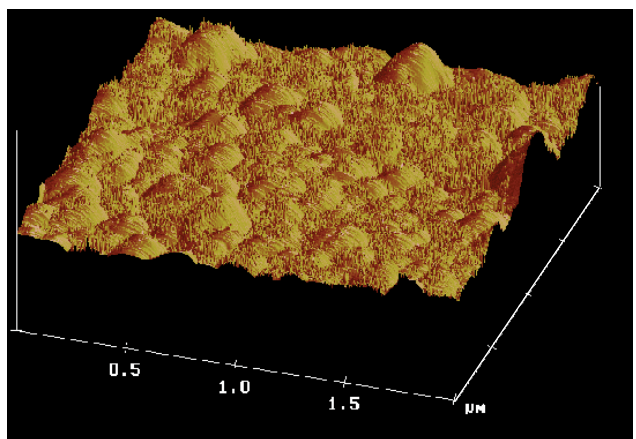

Figure 3. (a) AFM image of the $\mathrm{Ni}_{0.32} \mathrm{Fe}_{2.68} \mathrm{O}_{4}$ film prepared by the spin-spraying technique; $(b)$ 3D view profile of the same film.

(This figure is in colour only in the electronic version)

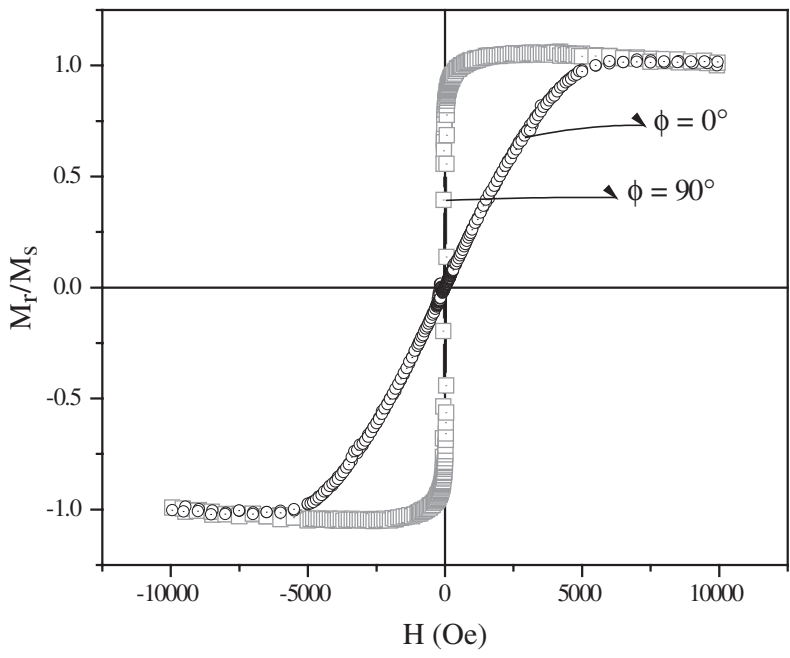

Figure 4. Typical magnetization curve measured at $300 \mathrm{~K}$ for the $\mathrm{Ni}_{0.32} \mathrm{Fe}_{2.68} \mathrm{O}_{4}$ film with two orientations of the film with respect to the magnetic field.

The topographical features of the surface of the nickel ferrite films were investigated by AFM. A representative AFM profile corresponding to the $\mathrm{Ni}_{0.32} \mathrm{Fe}_{2.68} \mathrm{O}_{4}$ film with a thickness of $500 \mathrm{~nm}$ is displayed in figure 3 . The picture reveals a dense film with a good crystallinity constructed by spherical grains with a narrow distribution of size, typically ranging between 200 and $400 \mathrm{~nm}$, grown in the direction normal to the substrate surface.

The data are in good agreement with the experimental SEM observations. Furthermore, the roughness measured in the scan range of $2 \mu \mathrm{m}$ is about $75 \mathrm{~nm}$, which demonstrates that the deposited films are fairly flat. Magnetic properties were determined at room temperature by applying a magnetic field both parallel $\left(\phi=0^{\circ}\right)$ and perpendicular $\left(\phi=90^{\circ}\right)$ to the normal of the film plane. As seen in figure 4 , the hysteresis loops for the two orientations of the field with respect to the film plane have different shapes, which indicate the presence of an in-plane magnetic anisotropy.

The values of the coercivity, squareness ratio SQ $\left(\mathrm{SQ}=M_{\mathrm{r}} / M_{\mathrm{S}}\right)$, the positions of the FMR peaks, saturation magnetization $M_{\mathrm{S}}$ and anisotropy constant $K_{1}$ of the nickel ferrite films investigated are summarized in table 1. According to the experimental data, the squareness, measured in both the in-plane and out-of-plane directions, and the saturation magnetization $M_{\mathrm{s}}$ decrease with increase in the nickel content, whereas the coercivity of the films remains almost unchanged. Additionally, the squareness measured out of plane is almost three times smaller than that measured in a direction parallel to the film plane. This difference between the squareness values for the two orientations suggests the existence of a planar uniaxial anisotropy.

To obtain better insight into the nature of the anisotropy of the nickel ferrite films, FMR experiments were performed at room temperature. As shown in figure 5, all films present distinct resonance peaks for each orientation of the films with respect to the external magnetic field. The linewidth of the resonance peaks were found to vary from 116 to 240 Oe for a parallel orientation of the field with respect to the magnetic field, whereas for a perpendicular orientation they range from 220 to 400 Oe. Additionally, as seen from the second derivative FMR signal (inset of figure 5), the absence of multiple resonances also suggests that the films are magnetically homogeneous [12]. The saturation magnetization is found to decrease monotonically upon increasing the $\mathrm{Ni}$ content of the films and the values obtained are in good agreement with the data reported in the literature for thin films and the bulk material [13]. For example, the saturation magnetization of $\mathrm{NiFe}_{2} \mathrm{O}_{4}$ thin films obtained by a dip-coating process was found to be $196 \mathrm{emu} \mathrm{cm}^{-3}$ [14], whereas $\mathrm{NiFe}_{2} \mathrm{O}_{4}$ thin films obtained by thermal decomposition of metal acetyl-acetonates have a saturation magnetization of $318 \mathrm{emu} \mathrm{cm}^{-3}$ [15]. Additionally, the values of the anisotropy constant $K_{1}$, calculated from the $\mathrm{H}_{\perp}$-FMR peaks are very close to the value reported for the bulk material $\mathrm{NiFe}_{2} \mathrm{O}_{4}$, namely $-4 \times 10^{4} \mathrm{erg} \mathrm{cm}^{-3}$ [16].

Figure 6 shows the angular dependence of the coercivity and squareness, where the abscissa $\phi$ represents the azimuthal angle between the direction of the magnetic field and the normal to the film surface. As seen in figure 6, in the angular interval of $0^{\circ}-90^{\circ}$, the coercivity initially increases from 15 Oe $\left(\phi=0^{\circ}\right)$ to $110 \mathrm{Oe}\left(\phi=45^{\circ}\right)$ and then decreases abruptly to 50 Oe $\left(\phi=75^{\circ}\right)$.

A similar behaviour is observed for angles between $90^{\circ}$ and $180^{\circ}$, but in this angular range the maximum of the coercivity reaches about 100 Oe for $\phi=33^{\circ}$. Such a 'M'-shaped $H_{\mathrm{c}}(\phi)$ curve follows neither the ideal domain movement mode (a $1 / \cos \phi$ curve) nor the Stoner-Wohlfarth rotational mode and could be ascribed rather to a magnetization reversal mechanism occurring by a nucleation and growth 
Table 1. Magnetic characteristics of $\mathrm{Ni}_{x} \mathrm{Fe}_{3-x} \mathrm{O}_{4}$ films processed by the spin-spraying method.

\begin{tabular}{lllllllll}
\hline & & \multicolumn{5}{c}{$\begin{array}{c}\text { FMR } \\
\text { peak }(\mathrm{Oe})\end{array}$} \\
\cline { 5 - 7 } \cline { 5 - 7 } Film composition & $H_{\mathrm{c}}(\mathrm{Oe})$ & $\left(M_{\mathrm{r}} / M_{\mathrm{s}}\right)_{\|}$ & $\left(M_{\mathrm{r}} / M_{\mathrm{s}}\right)_{\perp}$ & $\mathrm{H}_{\|}$ & $\mathrm{H}_{\perp}$ & & $M_{\mathrm{s}}$ & $K_{1} \times 10^{4}$ \\
\hline $\mathrm{Ni}_{0.05} \mathrm{Fe}_{2.95} \mathrm{O}_{4}$ & 73 & 0.727 & 0.21 & 1575 & 8926 & 436 & -2.32 \\
$\mathrm{Ni}_{0.09} \mathrm{Fe}_{2.91} \mathrm{O}_{4}$ & 68 & 0.681 & 0.16 & 1724 & 7182 & 299 & -2.27 \\
$\mathrm{Ni}_{0.26} \mathrm{Fe}_{2.74} \mathrm{O}_{4}$ & 70 & 0.641 & 0.12 & 1666 & 8056 & 369 & -3.02 \\
$\mathrm{Ni}_{0.32} \mathrm{Fe}_{2.68} \mathrm{O}_{4}$ & 68 & 0.659 & 0.21 & 1696 & 7492 & 324 & -2.61 \\
\hline
\end{tabular}

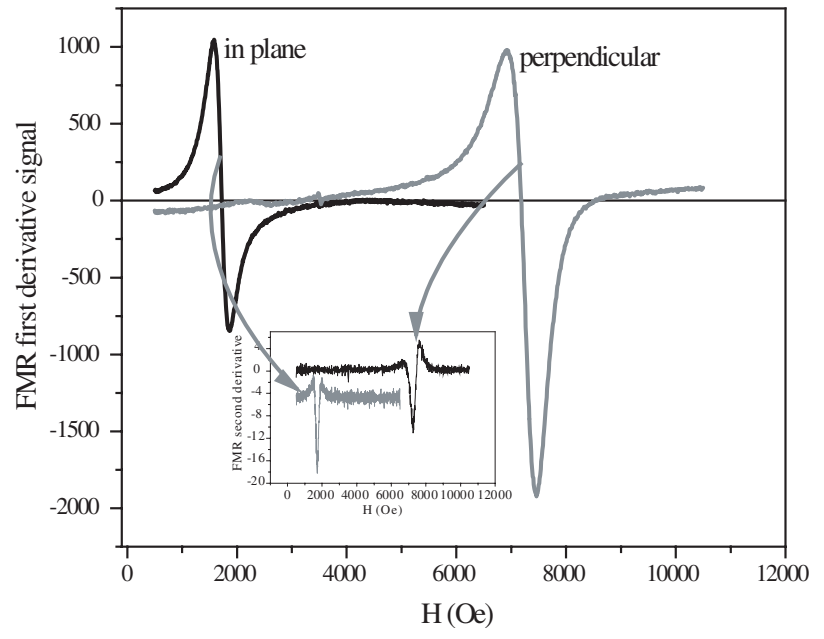

Figure 5. FMR peaks for the $\mathrm{Ni}_{0.32} \mathrm{Fe}_{2.68} \mathrm{O}_{4}$ film measured with two orientations of the film with respect to the magnetic field.

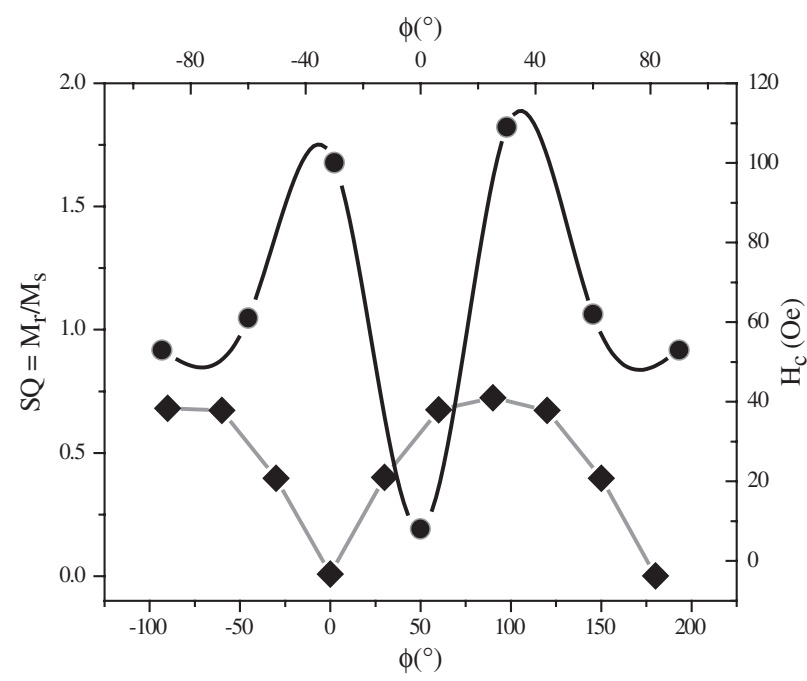

Figure 6. The angular dependence of the coercivity (circles) and squareness (squares) of a $400 \mathrm{~nm} \mathrm{Ni} \mathrm{Ni}_{0.32} \mathrm{Fe}_{2.68} \mathrm{O}_{4}$ film in a magnetic field making are angle $\phi$ with the normal of the film.

of reverse domains. These processes can be favoured by both surface irregularities and physical/chemical defects, which, in turn, induce a decrease of the magneto-crystalline anisotropy. Additionally, the M-type $H_{\mathrm{c}}(\phi)$ curve also indicates the existence of an in-plane anisotropy axis [17]. Other systems displaying a similar behaviour were previously reported in the literature and include prismatic Ni nanowires [18], Ni sphere arrays [19] and CoNi films [20]. The corresponding angular

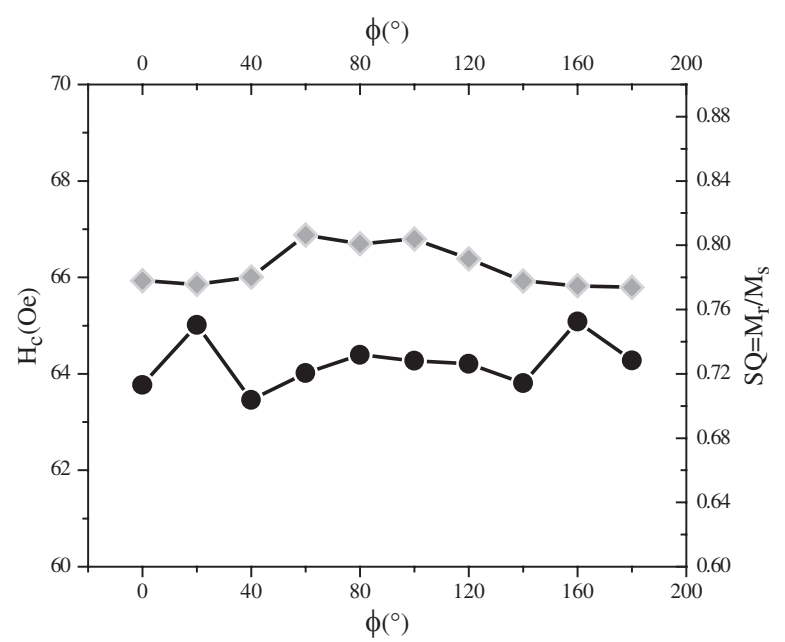

Figure 7. The angular dependence of the squareness and coercivity of a $400 \mathrm{~nm} \mathrm{Ni}{ }_{0.32} \mathrm{Fe}_{2.68} \mathrm{O}_{4}$ film rotated in a magnetic field parallel to the film plane.

variation of the squareness as illustrated in figure 6 shows a decrease from 0.4 (for $\phi=150^{\circ}$ ) to 0 at the field normal $(\phi=0)$, then an increase to SQ $=0.7$ when the field is applied parallel to the field plane $\left(\phi=90^{\circ}\right)$ followed by a second decrease to SQ $=0$ for $\phi=180^{\circ}$. Such a $|\cos \phi|$ angular dependence of the squareness also proves the existence of an in-plane uniaxial anisotropy in the nickel ferrite films [20].

However, magnetization measurements when the magnetic field was applied parallel to the film plane, with the film rotating about its own normal, did not reveal noticeable differences between the corresponding hysteresis loops-that is, all in-plane directions are equivalent (figure 7). This indicates that the uniaxial anisotropy that is eventually developed during the film formation is randomly oriented. Consequently, the effect of the centrifugal force acting on the rotating substrate during the film deposition should presumably be considered for the further development of oriented in-plane anisotropy in these films.

\section{Conclusions}

We prepared highly crystalline nickel ferrite films with different chemical compositions by the spin-spraying method. Highly homogeneous films are constructed by spherical 200-400 nm grains and exhibit room-temperature magnetism with an in-plane easy axis, as confirmed by VSM and FMR experiments. As revealed by the experimental data, the magnetic properties of the samples are mainly dominated by the shape anisotropy. Suitable experiments to further 
explore the origin of the anisotropy in the spin-sprayed nickel ferrite films are currently underway and will be presented in a forthcoming paper.

\section{Acknowledgments}

This work was supported by DOD/DARPA through Grant No MDA 972-97-1-0003. The authors gratefully acknowledge the help provided by Dr A Vovk with measurements of the film thicknesses and thank Dr Matt Tarr for support and helpful discussions on ICP measurements.

\section{References}

[1] Wane I, Cosset F, Bessaudou A, Celerier A, Girault C, Decossas J L and Vareille J C 1999 EUROMAT 99 Biannual Meeting of the Federation of European Materials Societies (FEMS) (Munich, Germany, 27-30 September 1999) vol 9, pp 54-61

[2] Ravinder D, Kumar K V and Reddy A V R 2003 Mater. Lett. 574162

[3] Zhang H Y, Gu B X, Zhai H R and Lu M 1994 Phys. Status Solidi a 143399

[4] Tachiki M, Noda M, Yamada K and Kobayashi T 1998 J. Appl. Phys. 835351
[5] Duque J G dos S, Macedo M A, Moreno N O, Lopez J L and Pfanes H D 2001 J. Magn. Magn. Mater. 226-230 1424

[6] Cheng F, Peng Z, Liao Z C and Yan C 1999 Thin Solid Films 339109

[7] Shu-Hong Y and Yoshimura M 2000 Chem. Mater. 123805

[8] Matsushita N, Chong C P, Mizutani T and Abe M 2002 IEEE Trans. Magn. 383156

[9] Abe M 2000 Electrochim. Acta 45337

[10] Taheri M, Carpenter E E, Cestone V, Miller M M, Raphael M P, McHenry M E and Haris V G 2002 J. Appl. Phys. 91 7595

[11] Matsushita N, Chong C P, Mizutani T and Abe M 2002 J. Appl. Phys. 917376

[12] Thalisa S H, Yoo K C, Abe M and Itoh T 1988 J. Appl. Phys. 645819

[13] Lax B and Buton K J 1962 Microwave Ferrites and Ferrimagnetics (New York: McGraw-Hill)

[14] Tsuchiya T, Yamashiro H, Sei T and Inamura T 1992 J. Mater. Sci. 273645

[15] Itoh H, Takeda T and Naka S 1986 J. Mater. Sci. 213677

[16] Weisz R S 1954 Phys. Rev. 96800

[17] Soohoo R F 1965 Magnetic Thin Films (New York: Harper and Row)

[18] Sun L, Searson P C and Chien C L 2001 Appl. Phys. Lett. 794429

[19] Xu L, Tung L D, Spinu L, Zakhidov A, Baughman R and Wiley J B 2003 Adv. Mater. 151562

[20] Gau J S and Brucker C F 1985 J. Appl. Phys. 573988 